\title{
1 Carbon capture from pulverized coal power plant (PCPP): solvent \\ 2 performance comparison at an industrial scale
}

\section{Sharifzadeh Mahdi ${ }^{1}$, Bumb Prateek, Shah Nilay}

$4 \quad{ }^{a}$ Centre for Process Systems Engineering (CPSE), Imperial College London

\section{Abstract}

7 Coal is the most abundant fossil fuel on the planet. However, power generation from coal results in large amounts of greenhouse gas emissions. Solvent-based carbon capture is a relatively mature technology which can potentially mitigate these emissions. Although, much research has been done on this topic, single-point performance analysis of capture plant ignoring operational characteristics of the upstream power plant may result in unrealistic performance assessments. This paper introduces a new methodology to assess the performance of $\mathrm{CO}_{2}$ capture solvents. The problem is posed as retrofitting an existing pulverised coal power plant with post-combustion carbon capture using two solvents: CDRMax, a recently developed aminepromoted buffer salt (APBS) solvent by Carbon Clean Solutions Limited (CCSL) and the monoethanolamine (MEA) baseline solvent. The features of interest include model development and validation using pilot plant data, as well as optimization based design and control of the capture process. The emphasis is on integrated operation of the capture plant and the upstream coal-fired power plant, when the electricity load changes. The results suggest that optimal design and operation of capture plant can significantly mitigate the energetic penalties associated with carbon capture form the flue gas, while providing effective measures for comparing solvent performances under various scenarios.

Solvent-based $\mathrm{CO}_{2}$ capture; pulverized coal power plant (PCPP); Integrated process design and control; process retrofit; optimization under uncertainty.

\footnotetext{
${ }^{1}$ Corresponding Author: Dr Mahdi Sharifzadeh; Room C603, Roderic Hill Building, South Kensington Campus, Imperial College London, UK. SW7 2AZ. E-mail: mahdi@imperial.ac.uk ; Tel: +44(0)7517853422
} 


\section{Introduction}

26

The International Energy Agency (IEA) asserts that fossil fuels will remain the dominant sources of energy for a foreseeable future [1]. While coal is the most abundant source of fossil fuel on the planet, its exploitation for power generations results in large amount of greenhouse gas emissions.

Post-combustion solvent-based carbon capture is an end-of-pipe technology which can be integrated with the power plants and reduce $\mathrm{CO}_{2}$ emissions. This technology is already well-established for natural gas sweetening [2] (with differences in operating conditions) and compared to other capture technologies, requires minimal process modifications. Therefore, retrofitting the existing power generation stations with post-combustion carbon capture has been the focus of academic and industrial researchers. Recently a team of European researchers studied post-combustion from advanced supercritical pulverized coal power plants [3]. They reported a $12 \%$ reduction in the overall energy conversion efficiency, when $86.3 \%$ of the produced $\mathrm{CO}_{2}$ is captured. Similarly, the National Energy Technology Laboratory (NETL) in the US conducted a study [4] on carbon capture from pulverized coal Rankine cycle power plants. About $10.9 \%$ reduction in the overall energy conversion efficiency was reported when $90 \%$ of $\mathrm{CO}_{2}$ was separated from the flue gas. In addition, a significant increase in the required cooling water was observed. Desideri and Antonelli [5] proposed a simplified method for evaluation of the performance of coal-fired power plants when integrated with a $\mathrm{CO}_{2}$ capture plant. They observed that depending on the coal type, the flue gas composition and $\mathrm{CO}_{2}$ flowrate can change by up to $9 \%$ and $12 \%$, respectively. They concluded that the overall conversion efficiency decreases with the solvent specific heat of regeneration, percentage of the carbon in the coal and the percentage of the $\mathrm{CO}_{2}$ removal from the flue gas. The costs of $90 \% \mathrm{CO}_{2}$ removal was estimated to lie between $64 \$ /$ tonne $\mathrm{CO}_{2}$ and $44 \$ /$ tonne $\mathrm{CO}_{2}$ resulting in almost $100 \%$ increase in the cost of electricity (COE). Recently, Manzolini et al. [6] investigated the economic performance of a supercritical coal power plant and a natural gas combined cycle power plant. Their economic analysis methods were based on (1) historical data from similar projects, and (2) detailed costing analysis based on process flowsheeting, mass and energy balances. The significant difference between the results of two methodology (table 7 of that publication), illustrated the challenges associated with economic analyses. Goto et al. [7] studied post-combustion carbon capture from various co-fired power plants. they concluded that the efficiency losses associated with $\mathrm{CO}_{2}$ capture were around $10 \%$ and do not depend on the type (e.g., sub-critical, supercritical and ultrasupercritical) of steam cycle system. Hammond and Spargo, 
$\$ /$ tonne for the undiscounted cost of avoided $\mathrm{CO}_{2}$. They suggested that the introduction of a "floor price" for carbon can potentially make carbon capture technologies economic. Wang and Du [9], studied the economic viability of carbon capture and storage (CCS) from coal-fired power plants in China using the real options approach. They concluded that between various sources of uncertainties such as the carbon price, fossil fuel price, investment cost and government subsidies, the latter has the most significant effect in economic. Recently, Damartzis et al. [10] applied a module-based generalized design framework for synthesizing the configuration of $\mathrm{CO}_{2}$ capture process. The optimization decisions included the stream topologies, the heat redistribution and the cascades of desorption columns for several commercially available solvents. They reported significant potential for economic improvement (15\%-35\%) and reductions in the reboiler duty (up to $55 \%)$.

Furthermore, researchers in the field have focused on power plant efficiency and the method of process integration from a thermodynamic point of view. Efficient operation of power plants can significantly reduce the $\mathrm{CO}_{2}$ emissions. Fu et al. [11] identified combustion reactions, heat transfer between flue gas and water/steam, low temperature heat losses, and the steam cycle as the causes of irreversibilities in coal-fired power plants. By including these irreversibilities in their exergy analyses, they quantified the theoretical maximum as well as practical values for energy efficiency of the power plant. They concluded that solventbased $\mathrm{CO}_{2}$ capture is the second most important cause of efficiency loss after combustion irreversibilities. Oexmann et al. [12] analysed post-combustion carbon capture from coal-fired power plants. They argued that the operational setting which minimizes the solvent regeneration energy may not be necessarily optimal with respect to the overall energy efficiency. The method of integrating the capture process into the power plant affects the overall energy efficiency. Using heat integration and pinch analysis, Hanak et al. [13] suggested that $78.4 \%$ of the steam between the intermediate and low pressure steam turbines is needed for solvent regeneration. They conducted pinch analysis in order to analyse five heat integration schemes. Heat recovery from the fuel gas was identified as the most important energy-saving opportunity. Olaleye et al. [14] studied the implication of various processing units for exergy destruction. They compared process configurations including absorber with intercooler, splitflow to desorber, and a combination of both. The last scenario showed the most significant potential for reducing the exergy destruction. 
The heat integration schemes investigated in the literature include the method of steam extraction and condensate recycling [15], integrating compressor inter-coolers to the low pressure section of the steam cycle [16] or stripper reboiler [17], preheating combustion air using waste heat from the capture plant [18], and application of pressurized hot water instead of steam for solvent regeneration $[19,20]$. Furthermore, the $\mathrm{CO}_{2}$ concentration of the flue gas can be increased by recirculation of the exhaust gases $[19,21,22]$ or using a supplementary burner placed in the duct connecting the turbine exhaust and heat recovery steam generation (HRSG) system [21-23]. Other researchers have explored the implications of the process configuration on the capital investment and energy costs. It was shown that depending on the solvent heat of desorption, either a multi-pressure or vacuum desorber could be the optimal configuration [24]. Other configurations include the absorber with intercooling, condensate heating, evacuation using water ejector, stripper overhead compression, lean amine flash, split-amine flow to absorber and desorber, and their combinations. Le Moulleca, et al. [25] classified these configurations into three categories of (1) absorption enhancement, (2) heat integration and (3) heat pump applications. They enumerated twenty process configurations from the open literature and patents. In general, up to $37 \%$ energy saving in terms of the required reboiler steam was reported [26]. Recently, Wang et al., [27] reviewed the methods for process intensification. They concluded that a rotating packed bed (RPB) absorber/stripper can result in energy-saving due to enhanced transport phenomena. Karimi, et al [28], argued that a high degree of energy integration may result in poor dynamic behaviour, because in energy integrated processes, disturbances propagate in several paths. Therefore, a trade-off between energy saving and process controllability should be established [29].

Nevertheless, integrated operation of carbon capture processes may not be realizable without considering the main operational characteristics of the upstream power plants. Power plants are subject to drastic variations in the electricity demand. Examples of such variations include regular daily and hourly variations in the consumer demand or stochastic variations, for example due to extreme weather conditions or local events. It is expected that by the introduction of renewable energy resources, the fluctuations in the electricity grid will also increase on the supply side, as some of these new resources such as solar or wind have intermittent generation characteristics. Therefore, it is for the fossil-based power plants to operate flexibly and balance the supply deficit in order to meet the demand. Therefore, commercialization of new $\mathrm{CO}_{2}$ capture technologies strongly depends on their adaptability in order to remain integrated as the upstream power plant experiences variations in the electricity demand. Recently, the flexibility of solvent-based carbon capture processes has 
111 been the focus of various research groups. Brouwer et al. [30] constructed prospective scenarios for power

112 generation including renewable resources. They concluded that in future the power plants will encounter up to $38 \%$ higher variability in the residual load, which will result in about $1.6 \%$ reduction in their efficiency. Shah and Mac Dowell [31] studied the multi-period operation of a coal-fired power plant. They adapted a timevarying solvent regeneration strategy in order to minimize the costs of $\mathrm{CO}_{2}$ capture. Delarue, et al. [32] had a similar observation that flexible operation of capture plant would offer a better economy. Van der Wijka et al. [33] argued that the main benefit of flexible operation of carbon capture process is significant increase in the up reserve provision. Venting is economically attractive only if $\mathrm{CO}_{2}$ price is less than $41 € /$ tonne (45 $\$ /$ tonne). Solvent storage of up to 2 hours was also found economic. Oates et al. [34] demonstrated that flexible operation of capture process allows undersizing the regenerator, offering $35 \%$ reduction in total costs. Lawal, et al. [35] studied the dynamic performance of carbon capture from a coal-fired sub-critical power plant. They concluded that the capture plant has a slower dynamic response than the power plant, which can prolong the power plant start-up or load-change due to steam extraction. In addition, it was observed that the interactions between the control loops in the power plant and capture plant limit the overall process controllability. Bypassing the flue gas, solvent storage and stripper-bypass can potentially offer flexibility and economic savings [36, 37].

The key observation in all the aforementioned studies is that the power plant and capture plant have mutual interactions in terms of the flue gas flowrate and composition on one side and the steam required for solvent regeneration and condensate recycling on the other side. In addition, conversion efficiency of the overall system is a strong function of deviation from full-load operating point and steam extraction for solvent regeneration. Therefore, single point performance analyses may be misleading and the design and operation of capture processes must consider the uncertainties in the upstream power plant in terms of operational flexibility and variations in the electricity load. In the present paper, we explore model development and validation, scale-up, power plant integration and flexible operation of the capture processes. The research questions also include the interactions between the power plant and carbon capture plant, which have implications for the overall energy efficiency and operational flexibility. The study is tailored to the CDRMax (an amine-promoted buffer salt, APBS) solvent, recently developed by Carbon Clean Solutions Limited (CCSL) and the MEA reference solvent. However, the research methodology is general in nature and can offer effective standards for carbon capture performance analysis and solvent comparison. The rest of the paper is 

plant and capture plant are presented and discussed. Then, the capture process model is developed and validated using pilot plant data. These enable the application of an optimization framework for the problem of retrofitting an existing coal-fired power plant using solvent-based capture process. Finally conclusions are made with respect to the implications CDRMax and MEA reference solvent in terms of technical and energetic performance measures.

\section{Overall process block diagram}

The overall process block diagram is shown in Figure 1. This figure shows that the coal-fired power plant integrates with the carbon capture plant at three points. The flue gas is sent from the power plant to the capture plant for $\mathrm{CO}_{2}$ separation. In addition, the capture plant relies on the steam from the power plant for regeneration of the solvent and it returns the condensates to the power plant for reuse and further steam generation. Compression of the separated $\mathrm{CO}_{2}$ also requires electricity from the power plant.

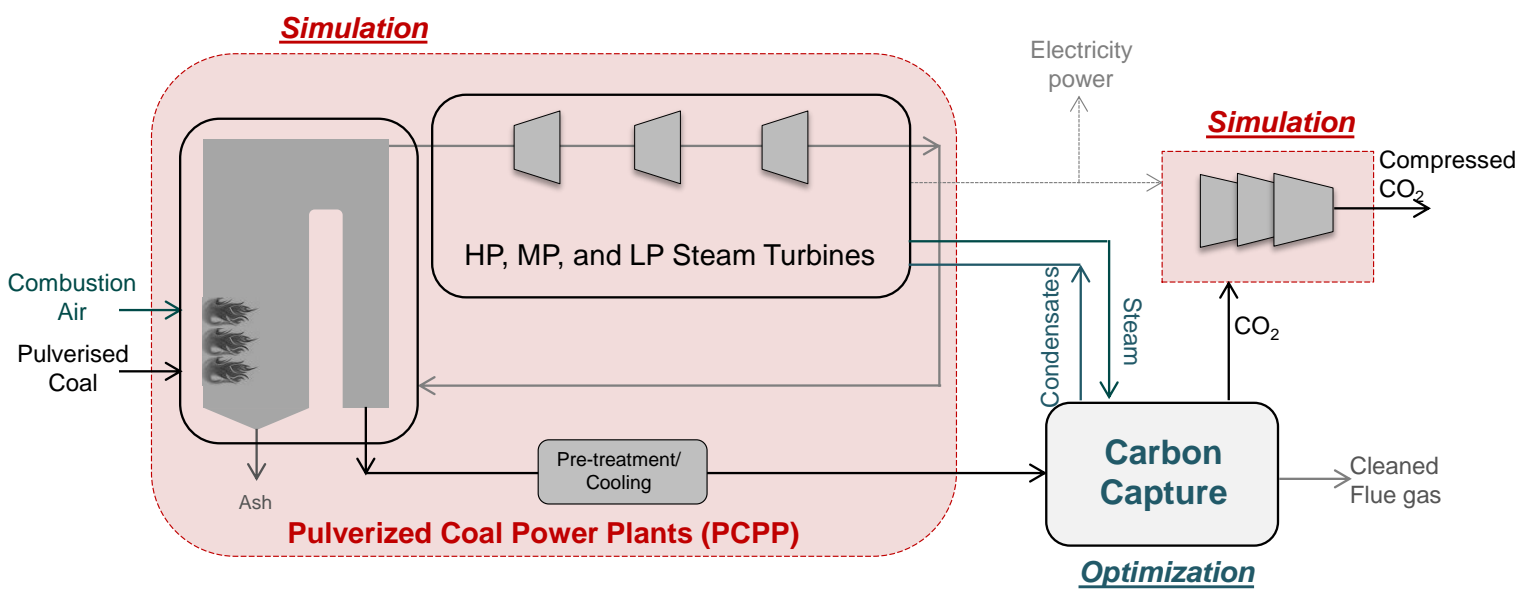

152

Figure 1. The block diagram for a pulverized power plant (PCPP) integrated with $\mathrm{CO}_{2}$ capture and $\mathrm{CO}_{2}$ compression

processes

\subsection{Process flow diagram of pulverized coal power plant (PCPP)}

Figure 2 shows the process flow diagram of the pulverized coal power plant (PCPP), in more detail. This process consists of a coal-fired steam generation system in which the heat released from combustion of coal is used for steam generation at supercritical conditions. Then, the generated steam is sent to the high pressure (HP) steam turbine for electricity generation. The exiting steam from the HP turbine is superheated using hot combustion gases before being sent to the medium pressure steam turbine. A part of the exiting steam from the medium pressure turbine is sent to the super-heater where its pressure and temperature are adjusted by 
mixing with the returning condensates before sending to the capture plant for solvent regeneration. The rest is fed to the low pressure steam turbine for electricity generation. Both HP and MP turbines are of the backpressure type. However, the LP turbine is a condensing turbine. The justification of using a condensing turbine is that the produced power is proportional to the pressure ratio between suction and discharge. Therefore, it is possible to enhance the produced work by creating vacuum conditions at the turbine discharge using a surface condenser. The condensates from the surface condenser and the condensates returning from the carbon capture plant are mixed, pressurized and recycled to the steam drums for further steam generation.

The flue gas is pre-treated before being sent to the capture process. The pre-treatment steps include a selective catalytic reduction (SCR) unit, followed by an electrostatic precipitator unit, followed by a flue gas desulphurization unit. In the SRC unit, the content of oxide and nitrogen dioxide of the flue gas are reduced to a certain level (10\%). The involved reactions are:

$$
\begin{aligned}
& 4 \mathrm{NO}+4 \mathrm{NH}_{3}+\mathrm{O}_{2} \rightarrow 4 \mathrm{~N}_{2}+6 \mathrm{H}_{2} \mathrm{O} \\
& \mathrm{NO}+\mathrm{NO}_{2}+2 \mathrm{NH}_{3} \rightarrow 2 \mathrm{~N}_{2}+3 \mathrm{H}_{2} \mathrm{O}
\end{aligned}
$$

The electrostatic precipitator unit removes the particles in order to ensure a certain level of ash concentration, e.g., $90 \%$ removal.

The desulphurization unit removed the sulphur oxide according to the following reaction with limestone.

$$
\mathrm{CaCO}_{3}+\mathrm{O}_{2}+2 \mathrm{H}_{2} \mathrm{O}+\mathrm{SO}_{2} \rightarrow \mathrm{CaSO}_{4}+2 \mathrm{H}_{2} \mathrm{O}+\mathrm{CO}_{2}
$$

\subsection{Process flow diagram of $\mathrm{CO}_{2}$ capture and compression sections}

Figure 3 shows the process flow diagram of the $\mathrm{CO}_{2}$ capture and compression sections. In the first column, the flue gas from the power plant comes into direct contact with cooling water in order to reduce its temperature and remove any entrained particles. In the next column, absorber, the $\mathrm{CO}_{2}$ is chemisorbed from the flue gas using the solvent. The $\mathrm{CO}_{2}$ rich solvent leaves the absorber from bottom. The cleaned flue gas exits from the absorber top and is sent to the water wash column. The aim of the water wash column is minimizing the solvent loss by absorbing the solvent spilled from the absorber top. The $\mathrm{CO}_{2}$-rich solvent from the bottom of the absorber is sent to the top of the desorber for $\mathrm{CO}_{2}$ stripping and solvent regeneration. The $\mathrm{CO}_{2}$-lean solvent from the desorber reboiler is recycled to the absorber for reuse and $\mathrm{CO}_{2}$ separation. The absorption reactions are exothermic and favour low temperatures. By comparison, the desorption reactions are endothermic and favour high temperatures. Therefore, there is an opportunity for heat integration between the hot $\mathrm{CO}_{2}$-lean stream and the cold $\mathrm{CO}_{2}$-rich stream. The separated $\mathrm{CO}_{2}$ from the desorber condenser is sent 
to the compression section. The compression section consists of seven compression stages. In each

189

190

191

192

193

194

195

196

197

198

199

200

201

202

203

204

205

206

207

208

209 compression stage, due to pressure enhancement, the temperature of the $\mathrm{CO}_{2}$ gas is increased, and needs to be cooled in the subsequent inter-stage cooler. As a result of sequential pressure enhancement and cooling, most of the water content of the $\mathrm{CO}_{2}$ stream is condensed in the early stages. The remaining water is removed using an adsorption process in the dehydrators. The compressed $\mathrm{CO}_{2}$ is sent from the last stage for storage and sequestration.

\section{Research methodology}

In the following, firstly the problem statement for retrofitting a pulverized coal power plant with carbon capture and compression is presented. Then, model development and validation for the $\mathrm{CO}_{2}$ capture process are discussed. The capture process model is scaled up and integrated to the power plant model. Then, an optimization framework is proposed to address the power plant retrofit problem. The main feature of interest is uncertainties in the power plant electricity demand that require flexible operation of the capture process in order to realize seamless process integration and retrofit. Finally, the implementation software tools are elaborated upon.

\subsection{Problem statement}

The present research addresses the problem of optimally retrofitting an existing pulverized coal power plant (PCPP) using solvent-based carbon capture, followed by $\mathrm{CO}_{2}$ compression. The specifications of an existing PCPP including the nominal operating conditions and the performance curves of process equipment under various partial load scenarios are given. It is intended to retrofit the power plant, so that $90 \%$ of the $\mathrm{CO}_{2}$ from coal combustion is captured and compressed to 111 bar. In addition, it is desired to ensure that the capture plant and its compression network remain operable at a wide range (i.e., 50\%-100\%) of electric power demands. 


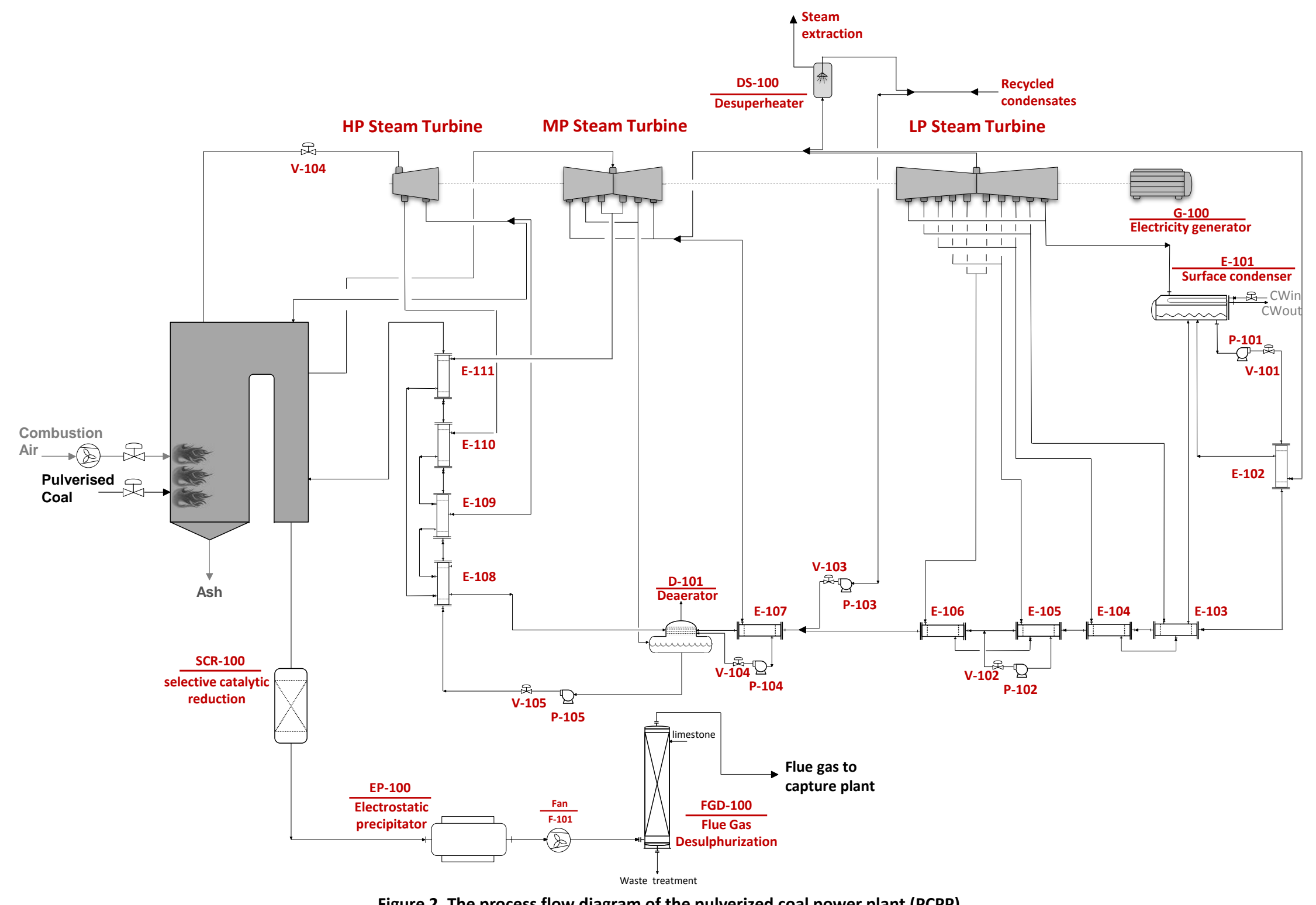

Figure 2. The process flow diagram of the pulverized coal power plant (PCPP) 


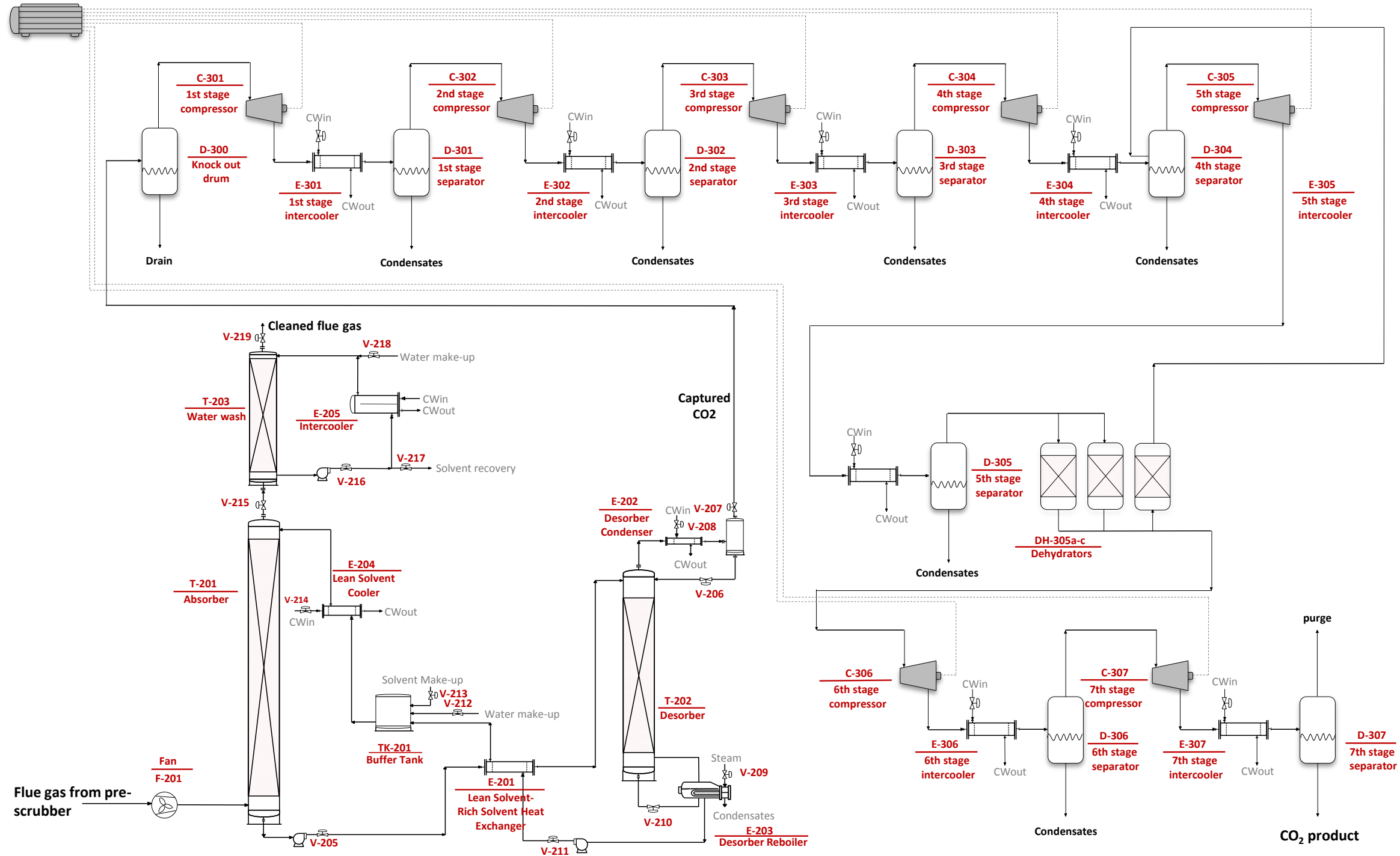

Figure 3. The process flow diagram of the $\mathrm{CO}_{2}$ capture and $\mathrm{CO}_{2}$ compression processes 


\subsection{Capture plant model development and validation}

215

216

217

218

219

220

221

222

The accurate modelling of the solvent-based $\mathrm{CO}_{2}$ capture processes for the purpose of solvent benchmarking and comparison requires a thorough understanding of the underlying physical and chemical phenomena. The present research benefits from rate-based modelling of gas-liquid contactors (i.e., absorber and desorber) and representation of reaction equilibria using the statistical associating fluid theory (SAFT), as discussed in the following.

\subsubsection{Rate-based modelling of gas-liquid contactors}

The rate-based model of the gas-liquid contactor is based on the two-film theory, as shown in Figure 4. Here, thermodynamic equilibrium is assumed only at the interface of vapour and liquid phases. Unlike equilibriumbased models, the exiting vapour phase is superheated and the exiting liquid phase is subcooled and they have different temperatures. The exchanged mass and energy between phases depend on the driving forces, transport coefficients, and the interfacial areas. Often, both convective and diffusive transport phenomena are involved and component-coupling effects need to be considered [38]. Various empirical correlations for calculating the mass transfer coefficient are proposed by researchers for random [39-41] and structured packings [41-43]. Finally, the bulk liquid and gas phases may have different flow configurations such as plug or mixed flows.

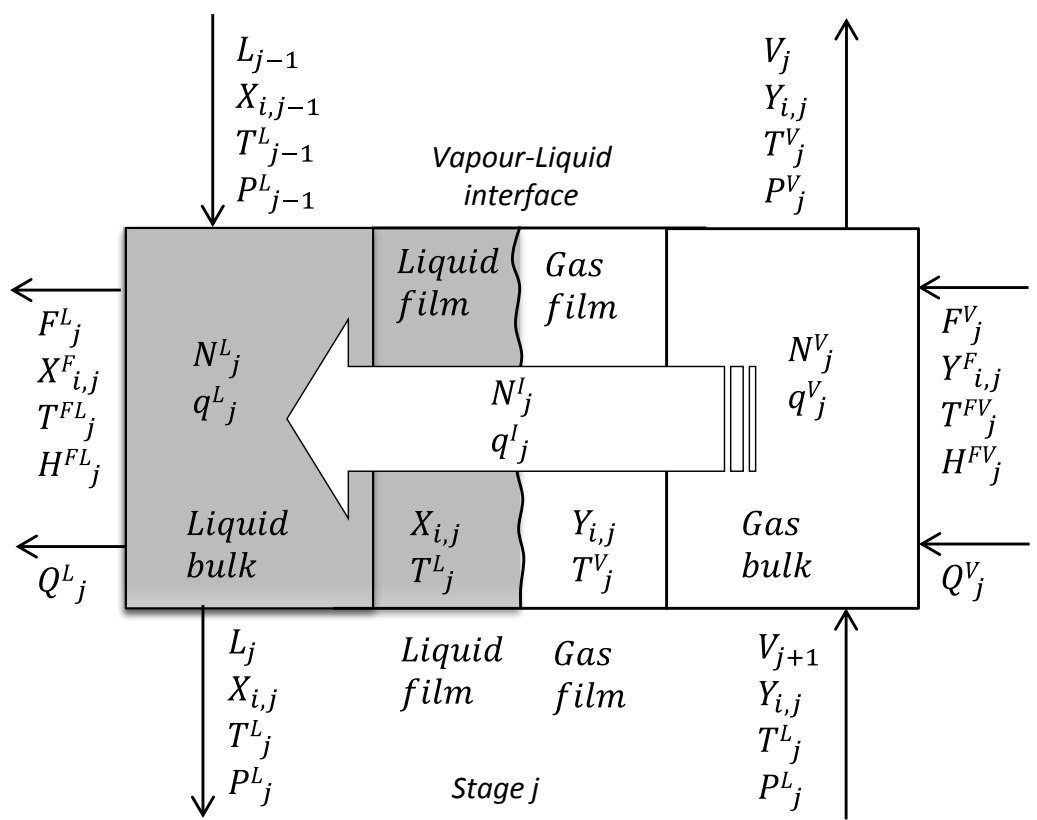

Figure 4. Two-film model used for modelling rate-based absorption and desorption of $\mathrm{CO}_{2}$ into and from solvent, [51]. 


\subsubsection{Reaction kinetics and thermodynamics}

233 A full space rate-based representation of $\mathrm{CO}_{2}$-solvent gas-liquid contactors requires detailed modelling of underlying chemical reactions and phase equilibrium conditions. For the case of $\mathrm{CO}_{2}$ capture using alkanolamines, this would require modelling a series of speciation reactions as follows [44]:

$$
\begin{aligned}
& 2 \mathrm{H}_{2} \mathrm{O} \leftrightharpoons \mathrm{H}_{3} \mathrm{O}^{+}+\mathrm{OH}^{-} \\
& \mathrm{CO}_{2}+\mathrm{H}_{2} \mathrm{O} \leftrightharpoons \mathrm{HCO}_{3}{ }^{-}+\mathrm{H}^{+} \\
& \mathrm{CO}_{2}+\mathrm{OH}^{-} \leftrightharpoons \mathrm{HCO}_{3}{ }^{-} \\
& \mathrm{CO}_{2}+\mathrm{RNH}_{2} \leftrightharpoons \mathrm{RNH}_{2}{ }^{+} \mathrm{CO}_{2}{ }^{-} \\
& \mathrm{RNH}_{2}{ }^{+} \mathrm{CO}_{2}{ }^{-}+\mathrm{RNH}_{2} \leftrightharpoons \mathrm{RNHCO}_{2}{ }^{-}+\mathrm{RNH}_{3}{ }^{+} \\
& \mathrm{RNHCO}_{2}{ }^{-}+\mathrm{H}_{2} \mathrm{O} \leftrightharpoons \mathrm{RNH}_{2}+\mathrm{HCO}_{3}^{-}
\end{aligned}
$$

236

where for the case of MEA, $\mathrm{R}=\mathrm{HO}-\mathrm{CH} 2-\mathrm{CH} 2-$. In the scheme above, reaction (1) represents water hydrolysis, reactions (2) and (3) are concerned with carbonic acid and bicarbonate formation, respectively. Reaction (4) represents the Zwitterion formation and reaction (5) is base catalysis. The two latter reactions are highly coupled as carbamate and protonated amines are tightly bonded. Therefore, reaction (4) and (5) can be shown abstractly as:

$$
\mathrm{CO}_{2}+2 \mathrm{RNH}_{2} \leftrightharpoons\left[\mathrm{RNHCO}_{2}^{-}+\mathrm{RNH}_{3}{ }^{+}\right]
$$

Reaction (7) is a reversible acid-base neutralization reaction. In this reaction, absorption of $\mathrm{CO}_{2}$ in alkanolamine solvent is exothermic; hence, it is possible to liberate $\mathrm{CO}_{2}$ by heating the $\mathrm{CO}_{2}$-rich solvent mixture and driving the reaction to left. Therefore, in theory, it is possible to regenerate the alkanolamine and recycle it for reuse in the absorber. In practice, a small amount of solvent make-up is supplied to compensate the losses associated with the solvent escape and degradation reactions.

Various thermodynamic models were proposed by researchers in order to describe the thermophysical properties of the mixture of $\mathrm{CO}_{2}$ absorbed into alkanolamines. These methods can be broadly classified to (1) activity-based models (derived from the Gibbs free energy), and (2) equation of state models (derived from the Helmholtz free energy). A frequently used activity-based model is Electrolyte Non-Random Two-Liquid (ENRTL) model in which the activity coefficient expressions of the original NRTL model are modified, and certain constraints regarding local like-ion repulsion and electroneutrality are imposed [45]. An alternative activitybased model is the Extended UNIQUAC model where the original UNIQUAC model was modified to account for ionic interactions [46]. A limitation of the aforementioned models is that they only describe the liquid phase 

applied for modelling the vapour phase. Alternatively, researchers attempted to use equations of state which can consider the presence of ionic components [47]. More recently, application of equations of state which are able to accommodate chemical equilibria such as association between molecules, has been the focus of various research groups [48- 50]. Here, the treatment is based on statistical associating fluid theory (SAFT), in which the Helmholtz free energy is correlated to the intermolecular association between the molecule segments [30]:

$$
\frac{A^{m i x}}{N k T}=\frac{A^{I D E A L}}{N k T}+\frac{A^{M O N O}}{N k T}+\frac{A^{C H A I N}}{N k T}+\frac{A^{A S S O C}}{N k T}
$$

261

In above, $N$ refers to the number of molecules, $k$ is the Boltzmann constant and $T$ is the mixture temperature. On the right hand side, the first term represents the ideal Helmholtz free energy and the three other terms refer to the residual contributions due to monomer interactions, formation of chains, and intermolecular interaction between associating sites. Then, given the Helmholtz free energy of the mixture, $A^{\text {mix }}$, it is possible to calculate other mixture properties (e.g., $\left.\mu_{i}=\left(\delta A / \delta N_{i}\right)_{T, V, N_{i \neq j}}\right)$. The association contribution is based on thermodynamic perturbation theory (TPT) [50], where by using intermolecular potential models (e.g., square well with variable range) and by adjusting their parameters (well depth and range), it is possible to fully characterize the strength of the associating sites. The idea is shown in Figure 5 for the case of reaction (4) and (5) [44]. In this approach, the reaction equilibria, the concentration of intermediate Zwitterion, and its thermophysical properties are not formulated anymore. Instead, $\mathrm{CO}_{2}$ and $\mathrm{MEA}$ are represented as associating molecule chains with two and six associating sites, respectively. Then, the concentration of $\mathrm{CO}_{2}$ in association with two MEA molecules represents the actual $\mathrm{CO}_{2}$ loading of the solvent at different temperatures and pressures. The combination of rate-based modelling and representation of chemical reactions using statistical associating fluid theory (SAFT) provides a consistent modelling approach. The justification is that for solvents such as MEA and CDRMax, the rate of reaction is significantly faster than the heat and mass transfer phenomena. Therefore, the knowledge of the rate of reactions at the gas-liquid interface is unnecessary and chemical equilibrium at the liquid-gas interface sufficiently describes the actual physical system behaviour. 


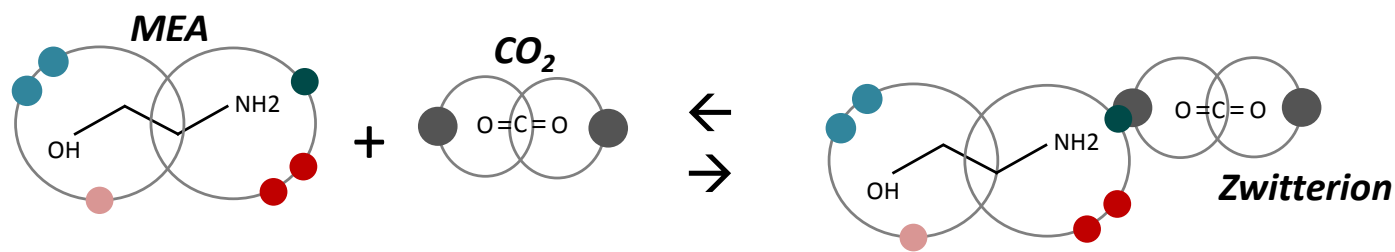

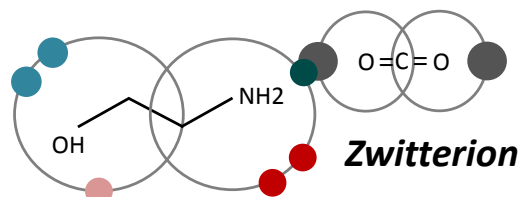
$+$

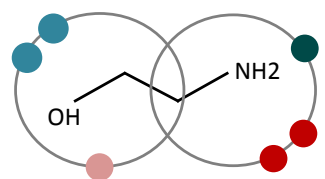

MEA

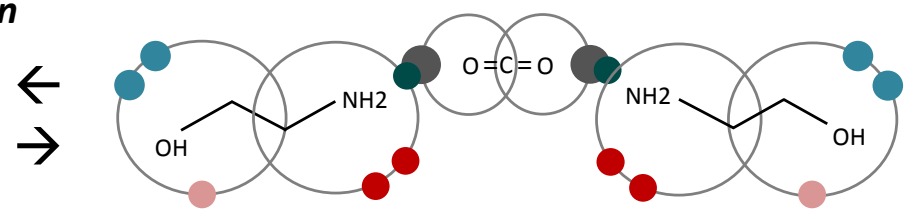

Carbamate

Figure 5. Schematic representation of Carbamate formation, [51]

This modelling approach offers several advantages, [51]; firstly unlike activity-based models, the same equation of state is used to describe both liquid and vapour phases. Secondly, the chemical equilibria are treated at the same level as phase equilibria. Furthermore, this approach results in significant model reduction because the speciation of intermediate ions is not included in the mathematical formulation and the uncertainties associated with their thermophysical parameters are disentangled from problem formulation. Most of all, the aforementioned approach establishes a connection between the chemical and physical behaviour of the mixture and the molecular structure of the involved materials. This is of particular importance to modelling new solvents as the required information can be acquired from the available data for the molecular segments of associating sites.

In the present research, rate-based gas-liquid contactor models were developed based on a combination of two-film theory and statistical associating fluid theory for potentials of variable range (SAFT-VR). The applied software tools were advanced modelling library gas-liquid contactors (AML-GLC) and gSAFT toolboxes developed by Process System Enterprise Ltd (PSE). The parametric values of thermodynamic models for the CDRMax are obscured in order to respect the confidentiality agreements with Carbon Clean Solutions Limited (CCSL) and Process System Enterprise Ltd (PSE). The aim of the present research is first to develop and validate an appropriate model using pilot plant data, then to evaluate the performance of the CDRMax solvent in comparison with the MEA benchmark solvent, at a large scale and when integrated optimally with a pulverized coal power plant. 


\subsubsection{Pilot plant studies and model validation}

299

In order to ensure effective benchmarking and model validation, three pilot plant runs were conducted using

300

the CDRMax solvent at the TNO pilot plant, in the Netherlands [52]. The benchmark for the MEA reference

301

solvent was selected from historical data from the US National Carbon Capture Center (NCCC) pilot plant

302

located in the Alabama, USA. The column specifications for the TNO pilot plant and the US NCCC pilot plant are

303 reported in Table 1. Table 2 shows the results of model validation for the CDRMax solvent. The different datasets have different solvent compositions. The model predictions are in very good agreement with the pilot plant data with respect to the captured $\mathrm{CO}_{2}$ and the solvent concentrations, giving confidence in the model's predictive capabilities. Minor discrepancies in the required steam and temperatures were attributed to lack of insulation or temperature measurement errors. Similarly, Table 3 shows very good agreement between the plot plant data and the simulation predictions for the case of the MEA solvent.

Table 1. Column Specifications, $[52,53]$.

\begin{tabular}{lllll}
\hline Column & Packing & Height of each bed $(\mathrm{m})$ & Diameter $(\mathrm{m})$ & Number of beds \\
\hline TNO pilot plant & & & & \\
Absorber & IMTP 50 - Random & 2.1 & 0.65 & 4 \\
Desorber & IMTP 50 - Random & 4.1 & 0.45 & 2 \\
\hline US NCCC pilot plant & & & & \\
Absorber & Mellapakplus M252Y-Structured & 6.1 & 0.66 & 3 \\
Desorber & Mellapakplus M252Y-Structured & 6.1 & 0.61 & 2 \\
\hline
\end{tabular}


Table 2. Model validation for the CDRMax solvent.

\begin{tabular}{|c|c|c|c|c|c|c|c|}
\hline & unit & $\begin{array}{l}\text { Data Set } \\
\# 1\end{array}$ & Simulation & $\begin{array}{l}\text { Data Set } \\
\# 2\end{array}$ & Simulation & $\begin{array}{l}\text { Data Set } \\
\# 3\end{array}$ & Simulation \\
\hline \multicolumn{8}{|c|}{ Flue gas to the absorber } \\
\hline Flowrate & $\mathrm{kg} / \mathrm{s}$ & 0.425 & 0.4246 & 0.36176 & 0.36176 & 0.3622 & 0.3622 \\
\hline Temperature & K & 315.22 & 315.22 & 315.85 & 315.85 & 313.55 & 313.55 \\
\hline Pressure & $\mathrm{Pa}$ & 104325 & 104325 & 104325 & 104325 & 104325 & 104325 \\
\hline $\mathrm{O}_{2}+\mathrm{N}_{2}$ & mol fraction & 0.81 & 0.81 & 0.81 & 0.81 & 0.81 & 0.81 \\
\hline $\mathrm{CO}_{2}$ & mol fraction & 0.107 & 0.107 & 0.107 & 0.107 & 0.107 & 0.107 \\
\hline $\mathrm{H}_{2} \mathrm{O}$ & mol fraction & 0.083 & 0.083 & 0.0835 & 0.0835 & 0.081 & 0.081 \\
\hline \multicolumn{8}{|l|}{ Reboiler } \\
\hline Pressure & $\mathrm{Pa}$ & 191325 & 191454 & 181325 & 180751 & 171325 & 171494 \\
\hline Temperature & K & 392.15 & 392.7 & 391.05 & 390.557 & 387.35 & 387.058 \\
\hline Duty & $\mathrm{J} / \mathrm{s}$ & 184005 & 184004 & 199054 & 198959 & 180003 & 180002 \\
\hline \multicolumn{8}{|l|}{ Condenser } \\
\hline Pressure & $\mathrm{Pa}$ & 189325 & 190325 & 179325 & 180325 & 169325 & 169368 \\
\hline Temperature & K & 296.15 & 296.16 & 296.15 & 296.15 & 296.15 & 296.15 \\
\hline \multicolumn{8}{|c|}{ Lean solvent to the absorber } \\
\hline Flowrate & $\mathrm{kg} / \mathrm{s}$ & 0.861 & 0.864 & 0.833 & 0.838 & 1.0556 & 0.98 \\
\hline Temperature & K & 301.15 & 301.15 & 300.15 & 300.15 & 313.15 & 313.15 \\
\hline $\mathrm{CO}_{2}$ & mass fraction & 0.043 & 0.043 & 0.029 & 0.029 & 0.045 & 0.045 \\
\hline $\mathrm{H}_{2} \mathrm{O}$ & mass fraction & 0.523 & 0.523 & 0.615 & 0.615 & 0.595 & 0.595 \\
\hline CDRMax & mass fraction & 0.435 & 0.435 & 0.356 & 0.356 & 0.361 & 0.361 \\
\hline \multicolumn{8}{|c|}{ Cleaned flue gas } \\
\hline $\mathrm{CO}_{2}$ & mol fraction & 0.011 & 0.023 & 0.0074 & 0.010 & 0.017 & 0.024 \\
\hline $\mathrm{O}_{2}$ & mol fraction & 0.089 & 0.099 & 0.073 & 0.078 & 0.0675 & 0.095 \\
\hline $\mathrm{N}_{2}$ & mol fraction & 0.768 & 0.749 & 0.7839 & 0.723 & 0.8145 & 0.738 \\
\hline $\mathrm{H}_{2} \mathrm{O}$ & mol fraction & 0.132 & 0.128 & 0.1357 & 0.189 & 0.101 & 0.142 \\
\hline $\mathrm{CO}_{2}$ recovered & $\mathrm{kg} / \mathrm{s}$ & 0.0592 & 0.0599 & 0.0528 & 0.0533 & 0.05 & 0.0506 \\
\hline Capture rate & $\%$ & 86.5 & 86.5 & 90.4 & 90.4 & 85.7 & 85.7 \\
\hline
\end{tabular}

312 


\begin{tabular}{|c|c|c|c|c|}
\hline & & Pilot Plant & Simulation \#1 & Simulation \#2 \\
\hline \multicolumn{5}{|l|}{ Flue gas to the absorber } \\
\hline Flowrate & $\mathrm{kg} / \mathrm{s}$ & 0.6279 & 0.6280 & 0.6280 \\
\hline Temperature & $\mathrm{K}$ & 316.56 & 316.56 & 316.56 \\
\hline Pressure & $\mathrm{Pa}$ & & & \\
\hline $\mathrm{N}_{2}+\mathrm{O}_{2}$ & Mass Fraction & 0.7862 & 0.7860 & 0.7860 \\
\hline $\mathrm{CO}_{2}$ & Mass Fraction & 0.1650 & 0.1650 & 0.1650 \\
\hline $\mathrm{H}_{2} \mathrm{O}$ & Mass Fraction & 0.0488 & 0.0488 & 0.0488 \\
\hline \multicolumn{5}{|l|}{ Lean Solvent - Absorber Inlet } \\
\hline Amine & Mass Fraction & 0.2965 & 0.2980 & 0.299 \\
\hline $\mathrm{CO}_{2}$ & Mass Fraction & 0.0628 & 0.0592 & 0.056 \\
\hline Water & Mass Fraction & 0.6407 & 0.6430 & 0.646 \\
\hline Total & $\mathrm{kg} / \mathrm{s}$ & 2.5200 & 2.5100 & 3.424 \\
\hline Lean solvent temperature & $\mathrm{K}$ & 316.15 & 316.15 & 316.15 \\
\hline Intercoolers outlet temperature & $\mathrm{K}$ & 316.15 & 316.15 & \\
\hline \multicolumn{5}{|l|}{ Reboiler Steam } \\
\hline Steam pressure & bar & 2.92 & 2.92 & 2.92 \\
\hline Steam temperature & $\mathrm{K}$ & 405.60 & 405.60 & 405.6 \\
\hline Steam flowrate & $\mathrm{kg} / \mathrm{s}$ & 0.18 & 0.15 & 0.206 \\
\hline \multicolumn{5}{|l|}{ Lean-Rich Heat Exchanger } \\
\hline Lean in & $\mathrm{K}$ & 388.87 & 388.9 & 389.4 \\
\hline Lean out & K & 331.4 & 338.9 & 348.1 \\
\hline Rich in & $\mathrm{K}$ & 327.91 & 330.4 & 338.8 \\
\hline Reboiler temperature & $\mathrm{K}$ & 385.6 & 388.0 & 389.4 \\
\hline Absorber bottom pressure & bar & 1.1 & 1.17 & 1.17 \\
\hline Absorber top pressure & bar & 1.04 & 1.04 & 1.01 \\
\hline desorber bottom (reboiler) pressure & bar & 1.71 & 1.71 & 1.71 \\
\hline Desorber top pressure & bar & 1.69 & 1.70 & 1.70 \\
\hline \multicolumn{5}{|l|}{ General specifications } \\
\hline $\mathrm{CO}_{2}$ capture target & $\%$ & 91.84 & 91.85 & 91.83 \\
\hline Inter-stage Cooling & & Yes & Yes & No \\
\hline
\end{tabular}


important measures that quantify the difficulties associated with $\mathrm{CO}_{2}$ separation from the flue gas in terms of the required heating and cooling duties, required packing, and solvent circulation. These measures are scaled with respect to the amount of pure $\mathrm{CO}_{2}$ captured, to become independent of the pilot plant throughput and economic assumptions (e.g. discount cash flow).

\section{Process Scale-up}

The validated model was applied for analysis at the large scale corresponding to the retrofitted power plant. The assumptions behind process scale up are summarized in the following. The bulk liquid and gas phases are assumed to be well-mixed at each stage (Figure 4). Phase equilibrium was assumed only at the vapour-liquid interface. It was assumed that the reaction kinetics are significantly faster than the heat and mass transfer rates and therefore, equilibrium chemical reactions sufficiently represent the species composition at the gasliquid interface. The effects of solvent degradation and heat losses were not considered. In practice, for largescale $\mathrm{CO}_{2}$ capture processes, achieving the aforementioned performances will require effective gas and liquid distributors. In addition, the process should be carefully insulated and the composition of the solvent should be tightly controlled using make-up.

\subsection{Solution algorithm: Simulation-optimization framework}

The aforementioned problem statement falls into the category of Integrated Process Design and Control (IPDC). It is notable that the IPDC methodology is not limited to grass-root design problems and can be applied for retrofitting existing processes in-part or as a whole. The motivation of the integrated process design and control, as opposed to sequential process design and control design, is due to the fact that when the details of process design are fixed, there is little room left to improve operational performance. Therefore, it is highly recommended that operational characteristics should be considered at the early design stages (i.e., process retrofit in the context of this research). However as discussed extensively by Sharifzadeh [29], the full-space formulation of integrated process and control design for large scale industrial problems such as the abovementioned retrofit problem results in numerically intractable optimization problems. Therefore, an objective of the present research was to identify 

tailored for the above-mentioned retrofit problem, as discussed in the following sections. The proposed optimization framework is shown in Figure 1. Here, the overall process is decomposed into three parts. These three parts are linked together through flow of materials and energy. As shown in Figure 1, the $\mathrm{CO}_{2}$ capture process receives the flue gas from the power plant and depends on the steam supply for regeneration of the solvent. The flowrate of flue gas depends on the electric power demand and changes as the power plant experiences variations. The variables involved in the optimal design of the $\mathrm{CO}_{2}$ capture process can be classified as (i) process design variables and (ii) process control variables. The differentiation is necessary as process design variables (such as the dimensions of process equipment) have a physical realization. After the process is designed, they are fixed and cannot be changed without costly process modification. By contrast the control variables (such as the flowrate of reboiler steam or the circulation rate of solvent) are variable during the process operation in order to adapt the capture process to the variations in the upstream power plant.

In the optimization framework, without loss of generality, the following solution algorithm was applied:

Step (1) The power plant model is run for a series of steady-state electricity load reduction $(100 \%, 75 \%$, and $50 \%$ ) scenarios, and a series of default values for the extracted steam and condensate recycle rates. The results of the simulation will determine the flowrate and composition of the flue gas in each scenario.

Step (2) Given the flowrate and composition of the flue gas at various load reduction scenarios, the design and control variables of the capture plant are optimized (as discussed in the following).

Step (3) The results of the optimization determine the optimal values of the extracted steam and recycled

371 Note that the amount of separated $\mathrm{CO}_{2}$ does not depend on the extracted steam values and therefore, modelling the compression section does not require iterative calculations. 


$$
\text { Objective }=\mathrm{E}\left(\mathrm{TAC}_{\mathrm{s}}\right)=\sum_{s=1}^{\mathrm{N}_{s}} \mu_{s} \times \mathrm{TAC}_{\mathrm{s}} \quad \text { Problem }-1
$$

\section{Subject to}

Constraints associated with first principles: equipment performances, thermodynamics models

Technical Constraints: Solvent degradation

Control Constraints: $90 \% \mathrm{CO}_{2}$ Capture, maximum turbine discharge temperature

Disturbances: Composition and flowrate of flue gas for various power load reduction scenarios

Design decision variables: The dimensions of absorber, desorber, and heat exchangers

Control (recourse) decision variables: Circulation flowrate, Reboiler steam flowrate

In the above formulation, $\mathbf{E}$ is the expected value, $\boldsymbol{s}$ is the index of the load reduction scenarios, $\boldsymbol{\mu}_{\boldsymbol{s}}$ is the likelihood of each scenario and $\mathbf{N}_{\boldsymbol{s}}$ is the total number of scenarios. TAC refers to the total annualized cost (TAC) of the capture plant, and was calculated as:

$$
\text { Total Annualized Costs }=\frac{\text { Fixed Capital investment }}{\text { Plant effective Life }}+\text { Total Annual Energy costs }
$$

where the value of 5 years was considered for the capture plant effective life, in order to combine the plant life and the time value of money. The costs of process equipment were calculated according to the costing correlations provided in [55]. A Lang factor of 6 was considered for estimating the total capital investment [56]. The utility costs considered were $37.02 \$ / \mathrm{MWh}$ for electricity [57], $0.048 \$ /$ tonne for cooling water [58], and $14.5 \$ /$ tonne for steam. The latter was estimated based on the electricity price and reduction in the power plant capacity due to steam extraction. The considered load reduction scenarios were $100 \%, 75 \%$ and $50 \%$. The considered scenarios were assumed to be equally likely.

From the optimization programming point of view, the above formulation conforms to a two-stage recoursebased optimization under uncertainty [59]. From the Control Engineering point of view the above formulation conforms to a steady-state inversely controlled process model (ICPM) [60-62]. The concept is shown in Figure 6. The model of the capture plant was inverted with respect to the constraint of $90 \%$ separation of $\mathrm{CO}_{2}$, and the required values for the reboiler steam and solvent circulation were optimized for each scenario. The model of the pulverised coal power plant (PCPP) was applied to accurately estimate the value of the disturbances in terms of the flowrate and composition of flue gas, as the electricity load changes. 
400

401

\section{2}

403

404

405

406

407

408

409

410

411

412

413

414

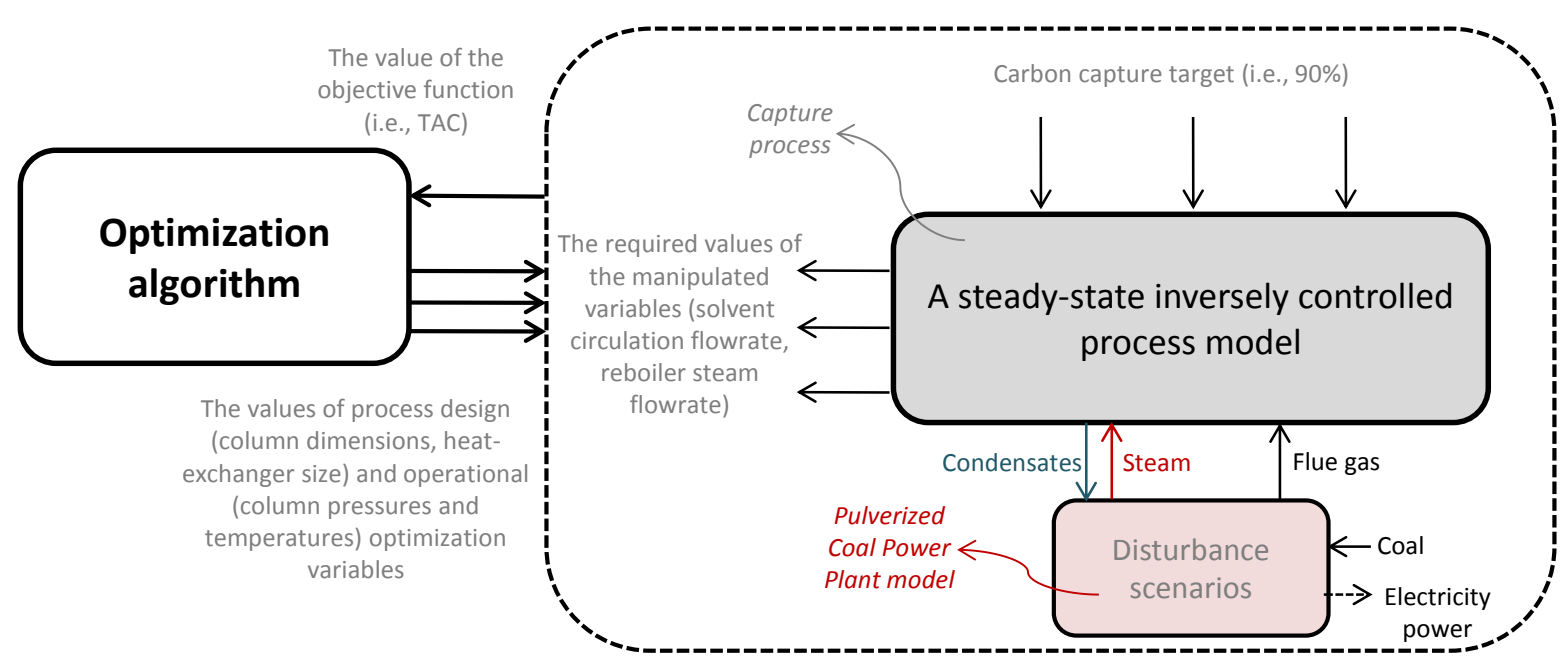

Figure 6. Integrated process design and control using a steady-state inversely controlled process model, [29]

\subsection{Model development and implementation software tools}

The NGCC power plant and compression process were modelled in gCCS [63], a software tool developed by Process Systems Enterprise Limited (PSE). The specification of the NGCC power plant model was received from PSE from one of their earlier industrial projects. The important characteristics of the developed model were calculation of the efficiency of the compressors and turbines using performance curves and calculation of material flowrates based on pressure differences. The capture plant model was developed using the Advanced Model Library for Gas-Liquid Contactors (AML: GLC) [64] and gSAFT [65].

As described extensively earlier, the main characteristics of the capture process model were rate-base modelling of mass and heat transfer phenomena and representation of chemisorption reactions using SAFT equation of state. The pulverised coal power plant (PCPP) was modelled using the gCCS model libraries. The pulverised coal boiler was modelled based on "Fixed reheat temperature". In this mode, the value of the temperature of the $(873.2 \mathrm{~K})$ is fixed and the required coal flowrate and combustion air are calculated, accounting the unburnt carbon in the ash. The justification is that the excessive heating would damage downstream equipment and the temperature of the HP steam leaving the boiler should be controlled. The coal composition and calorific value can be found in Table 2.2.1 of reference [3]. 


\section{Results}

418 This section presents and discusses the results of solvent performance analysis at the industrial scale. The features of interest include the overall energetic performance of the power plant with and without carbon capture and compression under various electricity scenarios. In addition the performances of the capture process when the power plant experiences load changes are studied for the PCMAX solvent and MEA reference solvent.

\section{3}

\subsection{Overall energy conversion efficiency and implications of carbon capture and compression}

Table 4 shows the summary of the results for the scenario in which the pulverized coal power plant is integrated with the capture and compression plants and the CDRMax solvent is used. Similar results are reported in Table 5 when the MEA reference solvent is used. In both scenarios, the flowrate of coal is gradually reduced from the nominal value of $65.9 \mathrm{~kg} / \mathrm{s}$ by almost $50 \%$ and the design and operation of the capture plant are optimized according to the simulation-optimization framework shown in Figures 1 and 6 . These Tables exhibit common observations regarding the implications of electricity load reduction for the integrated power generation and $\mathrm{CO}_{2}$ capture. In all scenarios, $\mathrm{CO}_{2}$ capture and compression impose energetic penalties in terms of the required steam for solvent regeneration and electric power needed for $\mathrm{CO}_{2}$ compression. These penalties exhibit themselves as reductions in the net produced electricity or decrease in the overall energy efficiency. Furthermore, as the electricity load is decreased the energy conversion efficiency also decreases, which should be attributed to the reduced efficiency of process equipment such as the steam generation system, turbines and compressors. The last line of Table 5 shows a comparison with the results of the CAESAR project [3]. While this table confirms that our model was in very good agreement with the CAESAR results for the PCPP without CCS, more than $2 \%$ improvement in the energy efficiency for the scenario with carbon capture and compression provides an evidence for the significant potential for integrated process design and control.

The implications of load reduction for operation of the capture plant features are more convoluted. To enable

441 the discussion more details are provided in Tables 6 and 7 which report the design and operational specifications for the load reduction scenarios, in the case of CDRMax and MEA solvents, respectively. As discussed in the process description, the boiler control strategy is to ensure the temperature of the steam leaving the pulverised coal boiler remains constant. As the electricity load is reduced, the pressure gradient 

across the power plant and the flowrates of the steam will decrease, accordingly. Therefore, in order to maintain the constant temperature of the returning steam, the ratio of the combustion air is marginally increased resulting in a decrease of the concentration of $\mathrm{CO}_{2}$ in the flue gas (Tables 4 and 5 ) from $20.5 \%$ to 18.5\%. On the contrary, more contact area (Shown by packing volume KPI in Tables 6 and 7) becomes available between the gas and liquid phases. Then, it is for the optimization algorithm to adjust the solvent circulation rate and reboiler steam for each electricity load scenario and establish a trade-off between the capital investment and energy costs. Overall a minor decrease in the heating and cooling energy indicators and solvent circulation indicators are observed for the load reduction scenarios. Another important feature of interest is the design and operation of the absorber column. The absorber experiences the largest variations during load reduction due to drastic variations in the flue gas flowrates. While the desired extent of $\mathrm{CO}_{2}$ capture constrains the required gas-liquid contact area, a tall/thin column would result in very high pressure drops at full load operation and a short/fat column would result in short contact times of the gas and liquid phases during part load operation. Therefore, it was for the optimization algorithm to find a compromise design which satisfies the $\mathrm{CO}_{2}$ capture constraint and ensures process operability in all load reduction scenarios. Tables 6 and 7 suggest that the optimized columns were neither fat nor thin but almost square. Finally, a comparison between the KPIs in Tables 6 and 7 suggests that CDRMax features superior performance as it required up to $25 \%$ less steam, $61 \%$ less cooling water, about $58 \%$ less column packing and up to $31 \%$ less pumping energy (shown by solvent circulation rate), per unit mass of captured $\mathrm{CO}_{2}$. The justification for the superior performance of the CDRMax is due to the fact that it is an amine-promoted buffer salt (APBS) solvent. It offers dual advantages for efficient $\mathrm{CO}_{2}$ capture, which should be attributed to the fast kinetics of amines and the low regeneration energy of the buffer salt. The fast kinetics offer lower equipment sizes and the lower regeneration energy offers lower operating costs. The CDRMax solvent also offers high $\mathrm{CO}_{2}$ loading capacity and thus reduces the circulation rate significantly as compared to MEA benchmarks. 
Table 4. The results of flexible operation of the pulverized coal power plant for various electricity load, with and without $\mathrm{CO}_{2}$ capture and compression plants: CDRmax solvent.

\begin{tabular}{|c|c|c|c|c|c|}
\hline & & Nominal $^{a}$ & $100 \%$ load & $75 \%$ load & $50 \%$ load \\
\hline Coal flowrate & $\mathrm{kg} / \mathrm{s}$ & 65.9 & 65.9 & 50.3 & 35.2 \\
\hline Flue gas flowrate & $\mathrm{kg} / \mathrm{s}$ & 787.7 & 787.7 & 631.3 & 465.0 \\
\hline $\mathbf{N}_{\mathbf{2}}$ & Mass fraction & 0.6956 & 0.6956 & 0.6981 & 0.7005 \\
\hline $\mathrm{O}_{2}$ & Mass fraction & 0.0393 & 0.0393 & 0.0484 & 0.0572 \\
\hline $\mathrm{H}_{2} \mathrm{O}$ & Mass fraction & 0.0598 & 0.0598 & 0.0583 & 0.0568 \\
\hline $\mathrm{CO}_{2}$ & Mass fraction & 0.2052 & 0.2052 & 0.1952 & 0.1854 \\
\hline Generated power in PCPP & MW & 776.4044 & 680.5 & 510.7 & 341.9 \\
\hline Extracted steam & $\mathrm{kg} / \mathrm{s}$ & - & 169.5 & 121.2 & 81.1 \\
\hline Power consumed in compressors & MW & - & 44.62 & 33.58 & 23.45 \\
\hline Net produced electricity & MW & 776.4044 & 635.8 & 477.1 & 318.4 \\
\hline $\mathrm{CO}_{2}$ captured & $\mathrm{kg} / \mathrm{s}$ & 0 & 145.5 & 110.9 & 77.6 \\
\hline Energy content of feed (HHV) & MW & 1714.24 & 1714.24 & 1306.6 & 914.13 \\
\hline Overall conversion efficiency & $\%$ & 45.29 & 37.09 & 36.51 & 34.83 \\
\hline
\end{tabular}

471

472

473

474

Notes: ${ }^{a}$ Nominal refers to the standalone scenario where the power plant is operated at its nominal operating point without $\mathrm{CO}_{2}$ capture and compression plants.

Table 5. The results of flexible operation of the pulverized coal power plant for various electricity load, with and without $\mathrm{CO}_{2}$ capture and compression plants: MEA baseline solvent.

\begin{tabular}{|c|c|c|c|c|c|}
\hline & & Nominal $^{\mathrm{a}}$ & $100 \%$ load & $75 \%$ load & $50 \%$ load \\
\hline Coal flowrate & $\mathrm{kg} / \mathrm{s}$ & 65.9 & 65.9 & 50.3 & 35.2 \\
\hline Flue gas flowrate & $\mathrm{kg} / \mathrm{s}$ & 787.7 & 787.7 & 631.3 & 465.0 \\
\hline $\mathbf{N}_{2}$ & Mass fraction & 0.6956 & 0.6956 & 0.6981 & 0.7005 \\
\hline $\mathrm{O}_{2}$ & Mass fraction & 0.0393 & 0.0393 & 0.0484 & 0.0572 \\
\hline $\mathrm{H}_{2} \mathrm{O}$ & Mass fraction & 0.0598 & 0.0598 & 0.0583 & 0.0568 \\
\hline $\mathrm{CO}_{2}$ & Mass fraction & 0.2052 & 0.2052 & 0.1952 & 0.1854 \\
\hline Generated power in PCPP & MW & 776.4 & 659.3 & 494.5 & 329.0 \\
\hline Extracted steam & $\mathrm{kg} / \mathrm{s}$ & - & 217.90 & 159.51 & 103.16 \\
\hline Power consumed in compressors & MW & - & 44.62 & 33.58 & 23.45 \\
\hline Net produced electricity & MW & 776.4 & 624.6 & 468.5 & 311.0 \\
\hline $\mathrm{CO}_{2}$ captured & $\mathrm{kg} / \mathrm{s}$ & 0 & 145.5 & 110.9 & 77.6 \\
\hline Energy content of feed (HHV) & MW & 1714.2 & 1714.2 & 1306.6 & 914.1 \\
\hline Overall conversion efficiency & $\%$ & 45.29 & $35.79 \%$ & $35.21 \%$ & $33.36 \%$ \\
\hline $\begin{array}{l}\text { Benchmark Overall conversion } \\
\text { efficiency from literature[3] }\end{array}$ & $\%$ & 45.5 & 33.4 & - & - \\
\hline
\end{tabular}

Notes: ${ }^{a}$ Nominal refers to the standalone scenario where the power plant is operated at its nominal operating point without $\mathrm{CO}_{2}$ capture and compression plants. 
Table 6. The results of CDRmax solvent for various load reduction scenarios

\begin{tabular}{|c|c|c|c|c|}
\hline & & $100 \%$ load & $75 \%$ load & $50 \%$ load \\
\hline Absorber & & 20.78 & 20.78 & 20.78 \\
\hline Diameter & $\mathrm{m}$ & 21.74 & 21.74 & 21.74 \\
\hline Length & $\mathrm{m}$ & & & \\
\hline \multicolumn{5}{|l|}{ Lean-Rich Heat Exchanger } \\
\hline Area & $\mathrm{m}^{2}$ & 52572.4 & 52572.4 & 52572.4 \\
\hline Lean inlet temperature & $\mathrm{K}$ & 383.2 & 383.1 & 383.3 \\
\hline Lean outlet temperature & K & 331.1 & 330.5 & 329.6 \\
\hline Rich inlet temperature & $\mathrm{K}$ & 328.4 & 328.6 & 328.8 \\
\hline Rich outlet temperature & $\mathrm{K}$ & 380.1 & 380.7 & 381.8 \\
\hline \multicolumn{5}{|l|}{ Desorber } \\
\hline Diameter & $\mathrm{m}$ & 15.61 & 15.61 & 15.61 \\
\hline Length & $\mathrm{m}$ & 9.95 & 9.95 & 9.95 \\
\hline \multicolumn{5}{|l|}{ Lean Solvent to absorber } \\
\hline Flowrate & $\mathrm{kg} / \mathrm{s}$ & 4098.65 & 3396.99 & 2367.65 \\
\hline Temperature & $\mathrm{K}$ & 313.15 & 313.15 & 313.15 \\
\hline Water & mass fraction & 0.5357 & 0.5357 & 0.5357 \\
\hline $\mathrm{CO}_{2}$ & mass fraction & 0.0403 & 0.0403 & 0.0403 \\
\hline CDRMax & mass fraction & 0.4069 & 0.4069 & 0.4069 \\
\hline \multicolumn{5}{|l|}{ Reboiler } \\
\hline Steam Flowrate & $\mathrm{kg} / \mathrm{s}$ & 153.22 & 122.43 & 83.41 \\
\hline Steam inlet pressure & $\mathrm{Pa}$ & 305000 & 305000 & 305000 \\
\hline Steam inlet temperature & $\mathrm{K}$ & 400.6 & 400.6 & 400.6 \\
\hline Condenser temperature & $\mathrm{K}$ & 313.15 & 313.15 & 313.15 \\
\hline $\mathrm{CO}_{2}$ captured & $\%$ & 90 & 90 & 90 \\
\hline Total Annualized Costs (TAC) & MM\$/year & 81.8 & - & - \\
\hline \multicolumn{5}{|l|}{ Key process indicators (KPIs) } \\
\hline Heating duty & $\mathrm{MJ} /$ tonne $\mathrm{CO}_{2}$ & 2418.3 & 2355.4 & 2287.0 \\
\hline Cooling duty & $\mathrm{MJ} /$ tonne $\mathrm{CO}_{2}$ & 2590.3 & 2567.3 & 2465.2 \\
\hline Packing Volume & $\mathrm{m}^{3} /\left(\right.$ tonne $\mathrm{CO}_{2} \times \mathrm{hr}$ ) & 18.9 & 23.1 & 32.9 \\
\hline Circulation rate & tonne solvent/tonne $\mathrm{CO}_{2}$ & 30.2 & 30.6 & 30.4 \\
\hline
\end{tabular}

482 
Table 7. The results of MEA baseline solvent for various load reduction scenarios

\begin{tabular}{|c|c|c|c|c|}
\hline & & $100 \%$ load & $75 \%$ load & $50 \%$ load \\
\hline \multicolumn{5}{|l|}{ Absorber } \\
\hline Diameter & $\mathrm{m}$ & 25.20 & 25.20 & 25.20 \\
\hline Length & $\mathrm{m}$ & 29.70 & 29.70 & 29.70 \\
\hline \multicolumn{5}{|l|}{ Lean-Rich Heat Exchanger } \\
\hline Area & $\mathrm{m}^{2}$ & 82190.8 & 82190.8 & 82190.8 \\
\hline Lean inlet temperature & $\mathrm{K}$ & 390.0 & 390.0 & 390.0 \\
\hline Lean outlet temperature & $\mathrm{K}$ & 352.3 & 349.2 & 345.2 \\
\hline Rich inlet temperature & $\mathrm{K}$ & 335.4 & 335.2 & 334.8 \\
\hline Rich outlet temperature & $\mathrm{K}$ & 373.0 & 375.7 & 379.1 \\
\hline \multicolumn{5}{|l|}{ Desorber } \\
\hline Diameter & $\mathrm{m}$ & 25.90 & 25.90 & 25.90 \\
\hline Length & $\mathrm{m}$ & 12.10 & 12.10 & 12.10 \\
\hline \multicolumn{5}{|l|}{ Lean Solvent to absorber } \\
\hline Flowrate & $\mathrm{kg} / \mathrm{s}$ & 6407.6 & 5024.8 & 3542.58 \\
\hline Temperature & $\mathrm{K}$ & 313.15 & 313.15 & 313.15 \\
\hline Water & mass fraction & 0.641 & 0.641 & 0.641 \\
\hline MEA & mass fraction & 0.297 & 0.297 & 0.297 \\
\hline $\mathrm{CO}_{2}$ & mass fraction & 0.062 & 0.062 & 0.062 \\
\hline \multicolumn{5}{|l|}{ Reboiler } \\
\hline Steam Flowrate & $\mathrm{kg} / \mathrm{s}$ & 217.90 & 159.51 & 103.16 \\
\hline Steam inlet pressure & $\mathrm{Pa}$ & 305000 & 305000 & 305000 \\
\hline Steam inlet temperature & $\mathrm{K}$ & 400.6 & 400.6 & 400.6 \\
\hline Lean Solvent Cooler temperature & & 313.15 & 313.15 & 313.15 \\
\hline $\mathrm{CO}_{2}$ capture target & $\%$ & $90 \%$ & $90 \%$ & $90 \%$ \\
\hline Total Annualized Costs (TAC) & MM\$/year & 102.5 & - & - \\
\hline \multicolumn{5}{|l|}{ Key process indicators (KPIs) } \\
\hline Heating duty & $\mathrm{MJ} /$ tonne $\mathrm{CO}_{2}$ & 3216.2 & 3050.4 & 2835.4 \\
\hline Cooling duty & $\mathrm{MJ} /$ tonne $\mathrm{CO}_{2}$ & 6615.4 & 6245.1 & 5715.6 \\
\hline Packing Volume & $\mathrm{m}^{3} /\left(\right.$ tonne $\mathrm{CO}_{2} \times \mathrm{hr}$ ) & 45.1 & 58.5 & 84.0 \\
\hline Circulation rate & tonne solvent/tonne $\mathrm{CO}_{2}$ & 43.6 & 44.3 & 44.9 \\
\hline
\end{tabular}

485

486

487

488

489

490

491 


\section{Conclusions}

493 The present research studied the scale up and integration of a solvent-based carbon capture process into a pulverised coal power plant (PCPP) for a novel solvent, CDRMax, and the MEA reference solvent. The aim was to establish and quantify the superior performance of the new solvent at an industrial scale and explore the benefits of integrated design and control. Furthermore, the present research provided in-depth insights into retrofit and flexible operation of pulverized coal power plants. It was also observed that PCPPs are less efficient at part load operational scenarios. In the present research, the method of integrated process design and control was adapted and solved using optimization under uncertainty. The overall total annual costs in terms of capital investment and energy costs were minimized while the process operability was ensured under all load reduction scenarios. Objective and reproducible comparison between various economic analysis is often challenging due to different scope of system analysis, modelling details and the economic estimation methods. Therefore, in the absence of economic data from industrial-scale demonstration plants, the present research applied key process indicators (KPIs) for comparison of solvents. In all scenarios the CDRMax performed better than the MEA reference solvent. While the comparative study was tailored to the aforementioned solvents, the research methodology is generic and provides effective standards and benchmarking criteria for new solvent development.

\section{Acknowledgements}

The authors would like to acknowledge the financial support by Carbon Clean Solutions (CCSL) under UKDepartment of Energy \& Climate Change (DECC) grant. We are also thankful to Process Systems Enterprise Ltd (PSE) for technical support and providing modelling libraries.

\section{References}

513 [1] International Energy Agency (IEA). World Energy Outlook. Paris: 2014.

514 [2] Bottoms RR, 1930. Process for Separating Acidic Gases. US patent no. 1783901.

515 [3] CAESAR project: European best practice guidelines for assessment of $\mathrm{CO}_{2}$ capture technologies [Internet]

516 [cited 2015 May 25], Project no.: 213206. Available from:

517 http://www.energia.polimi.it/news/D\%204 9\%20best\%20practice\%20guide.pdf Volume 1: Bituminous Coal and Natural Gas to Electricity Revision 2. November 2010, DOE/NETL2010/1397. 
[5] Desideri U, Antonelli M. A simplified method for the evaluation of the performance of coal fired power plant with carbon capture. Applied Thermal Engineering 2014; 64: 263-272.

[6] Manzolini G, Fernandez ES, Rezvani S, Macchi E, Goetheer ELV, Vlugt TJH. Economic assessment of novel amine based $\mathrm{CO} 2$ capture technologies integrated in power plants based on European Benchmarking Task Force methodology. Applied Energy 2015; 138: 546-558.

[7] Goto K, Yogo K, Higashii T. A review of efficiency penalty in a coal-fired power plant with post-combustion CO2 capture. Applied Energy 2013; 111: 710-720.

[8] Hammond GP, Spargo J. The prospects for coal-fired power plants with carbon capture and storage: A UK perspective. Energy Conversion and Management 2014; 86: 476-489.

[9] Wang X, Du L. Study on carbon capture and storage (CCS) investment decision-making based on real options for China's coal-fired power plants. Journal of Cleaner Production, 2015; in press. (doi:10.1016/j.jclepro.2015.07.112).

[10] Damartzis T, Papadopoulos Al, Seferlis P. Process flowsheet design optimization for various amine-based solvents in post-combustion $\mathrm{CO} 2$ capture plants. Journal of Cleaner Production. 2015; in press. (doi:10.1016/j.jclepro.2015.04.129).

[11] Fu C, Anantharaman R, Jordal K, Gundersen T. Thermal efficiency of coal-fired power plants: From theoretical to practical assessments. Energy Conversion and Management 2015; 105: 530-544.

[12] Oexmann J, Kather A, Linnenberg S, Liebenthal U. Post-combustion $\mathrm{CO} 2$ capture: chemical absorption processes in coal-fired steam power plants. Greenhouse Gases: Science and Technology 2012; 2(2): 8098.

[13] Hanak DP, Biliyok C, Yeung H, Białecki R. Heat integration and exergy analysis for a supercritical high-ash coal-fired power plant integrated with a post-combustion carbon capture process. Fuel 2014; 134:126139.

[14] Olaleye AK, Wang M, Kelsall G. Steady state simulation and exergy analysis of supercritical coal-fired power plant with $\mathrm{CO} 2$ capture. Fuel 2015; 151: 57-72.

[15] Lucquiaud M, Gibbins J. On the integration of $\mathrm{CO}_{2}$ capture with coal-fired power plants: A methodology to assess and optimise solvent-based post-combustion capture systems. Chemical Engineering Research and Design. 2011; 89: 1553-1571.

[16] Romeo LM, Bolea I, Y Lara, Escosa JM. Optimization of intercooling compression in $\mathrm{CO}_{2}$ capture systems. Applied Thermal Engineering. 2009; 29: 1744-1751.

[17] Karimi M, Hillestad M, Svendsen HF. Capital costs and energy considerations of different alternative stripper configurations for post combustion $\mathrm{CO}_{2}$ capture. Chemical Engineering Research and Design. 2011; 89: 1229-1236.

[18] Pfaff I, Oexmann J, Kather A. Optimised integration of post-combustion $\mathrm{CO}_{2}$ capture process in greenfield power plants. Energy. 2010; 35 (10): 4030-4041.

[19] Jonshagen K, Sipöcz N, Genrup M. A novel approach of retrofitting a combined cycle with post combustion $\mathrm{CO}_{2}$ capture, Journal of Engineering for Gas Turbines and Power. 2010; 133(1): 011703-1-011703-7.

[20] Khalilpour R, Abbas A. HEN optimization for efficient retrofitting of coal-fired power plants with postcombustion carbon capture. International Journal of Greenhouse Gas Control. 2011; 5: 189-199. 
[21] Biliyok $\mathrm{C}$, Yeung $\mathrm{H}$. Evaluation of natural gas combined cycle power plant for post-combustion $\mathrm{CO}_{2}$ capture integration, International Journal of Greenhouse Gas Control. 2013; 19: 396-405.

[22] Luo X, Wang M, Chen J. Heat integration of natural gas combined cycle power plant integrated with postcombustion $\mathrm{CO}_{2}$ capture and compression. Fuel. 2015; 151: 110-117.

[23] Li H, Ditaranto $\mathrm{M}$, Berstad D. Technologies for increasing $\mathrm{CO}_{2}$ concentration in exhaust gas from natural gas-fired power production with post-combustion, amine-based $\mathrm{CO}_{2}$ capture. Energy. 2011 ; 36 (2): 11241133.

[24] Oyenekan BA, Rochelle GT. Energy performance of stripper configurations for $\mathrm{CO}_{2}$ capture by aqueous amines. Industrial \& Engineering Chemistry Research. 2006; 45: 2457-2464.

[25] Le Moullec Y, Neveux T, Al Azki A, Chikukwa A, Hoff KA. Process modifications for solvent-based postcombustion $\mathrm{CO}_{2}$ capture. International Journal of Greenhouse Gas Control. 2014; 31: 96-112.

[26] Ahn H, Luberti M, Liu Z, Brandani S. Process configuration studies of the amine capture process for coalfired power plants. International Journal of Greenhouse Gas Control. 2013: 16; 29-40.

[27] Wang M, Joel AS, Ramshaw C, Eimer D, Musa NM. Process intensification for post-combustion CO2 capture with chemical absorption: A critical review. Applied Energy 2015; 158: 275-291.

[28] Karimi M, Hillestad M, Svendsen HF. Investigation of the dynamic behavior of different stripper configurations for post-combustion $\mathrm{CO}_{2}$ capture. International Journal of Greenhouse Gas Control. 2012; 7: 230-239.

[29] Sharifzadeh M. Integration of process design and control: A review. Chemical Engineering Research and Design. 2013; 91: 2515-2549.

[30] Brouwer AS, van den Broek M, Seebregts A, Faaij A. Operational flexibility and economics of power plants in future low-carbon power systems. Applied Energy 2015; 156: 107-128.

[31] Mac Dowell N, Shah N. The multi-period optimisation of an amine-based $\mathrm{CO}_{2}$ capture process integrated with a super-critical coal-fired power station for flexible operation. Computers \& Chemical Engineering, 2015; 74: 169-183.

[32] Delarue E, Martens P, D'haeseleer W. Market opportunities for power plants with post-combustion carbon capture. International Journal of Greenhouse Gas Control. 2012; 6: 12-20.

[33] van der Wijk PC, Brouwer AS, van den Broek M, Slot T, Stienstra G, van der Veen W, Faaij APC. Benefits of coal-fired power generation with flexible CCS in a future northwest European power system with large scale wind power. International Journal of Greenhouse Gas Control 2014; 28216-233.

[34] Oates DL, Versteeg P, Hittinger E, Jaramillo P. Profitability of CCS with flue gas bypass and solvent storage. International Journal of Greenhouse Gas Control 2014; 27: 279-288.

[35] Lawal A, Wanga M, Stephenson P, Obi O. Demonstrating full-scale post-combustion $\mathrm{CO}_{2}$ capture for coalfired power plants through dynamic modelling and simulation. Fuel. 2012; 101: 115-128.

[36] Chalmers H, Gibbins J. Initial evaluation of the impact of post-combustion capture of carbon dioxide on supercritical pulverised coal power plant part load performance. Fuel. 2007; 86: 2109-2123.

[37] Cohen SM, Rochelle GT, Webber ME. Optimal operation of flexible post-combustion $\mathrm{CO}_{2}$ capture in response to volatile electricity prices. Energy Procedia, 2011; 4: 2604-2611. 
[38] Seader JD, Henley EJ, Roper DK. Separation Process Principles (3rd edition). Hoboken, John Wiley \& Sons, Inc., 2013.

[39] Onda K, Takeuchi H, Okumoto Y. Mass transfer coefficients between gas and liquid phases in packed columns. Journal of Chemical Engineering of Japan. 1968; 1: 56-62.

[40] Bravo JL, Fair JR. Generalized correlation for mass transfer in packed distillation columns. Industrial and Engineering Chemistry Process Design and Development. 1982; 21: 162-170.

[41] Billet R, Schultes M. Predicting mass transfer in packed columns. Chemical Engineering \& Technology. 1993; 16: 1-9.

[42] Bravo JL, Rocha JA, Fair JR. Mass transfer in Gauze Packings. Hydrocarbon Processing. 1985; 64: 56-60.

[43] Bravo JL, Rocha JA, Fair JR. A comprehensive model for the performance of columns containing structured packings. Institution of Chemical Engineers Symposium Series, 1992, 128 (Distillation and Absorption '92, Vol. 1): A489-A507.

[44] Mac Dowell N, Llovell F, Adjiman CS, Jackson G, Galindo A. Modeling the Fluid Phase Behavior of Carbon Dioxide in Aqueous Solutions of Monoethanolamine Using Transferable Parameters with the SAFT-VR Approach. Industrial \& Engineering Chemistry Research. 2010; 49: 1883-1899.

[45] Chen CC, Song Y. Generalized electrolyte NRTL model for mixed solvent electrolyte systems. AIChE Journal. 2004; 50 (8): 1928-1941.

[46] Faramarzi L, Kontogeorgis GM, Thomsen K, Stenby EH. Extended UNIQUAC model for thermodynamic modeling of $\mathrm{CO} 2$ absorption in aqueous alkanolamine solutions. Fluid Phase Equilibrium. 2009; 282: 121132.

[47] Huttenhuis $\mathrm{P}$, Agrawal $\mathrm{N}$, Solbraa E, Versteeg $\mathrm{G}$. The solubility of carbon dioxide in aqueous $\mathrm{n}$ methyldiethanolamine solutions. Fluid Phase Equilibrium. 2008; 264 (1-2): 99-112.

[48] Fürst W, Renon H. Representation of excess properties of electrolyte solutions using a new equation of state. AIChE Journal. 1993; 39: 335-343.

[49] Button JK, Gubbins KE. SAFT prediction of vapour-liquid equilibria of mixtures containing carbon dioxide and aqueous monoethanolamine or diethanolamine. Fluid Phase Equilibria. 1999; 158-160: 175-181.

[50] Wertheim MS. Fluids with highly directional attractive forces. II. Thermodynamic perturbation theory and integral equations. Journal of Statistical Physics. 1984; 35: 35-47.

[51] Sharifzadeh M, Shah, N,. Comparative studies of $\mathrm{CO} 2$ capture solvents for gas-fired power plants: Integrated modelling and pilot plant assessments. International Journal of Greenhouse Gas Control, 2015; in press.

[52] Bumb P, Kumar R, Khakharia P, Goetheer E. Demonstration of advanced APBS solvent at $\mathrm{TNO}^{\prime} \mathrm{S}_{2}$ capture pilot plant. Energy Procedia, 2014; 63: 1657 - 1666.

[53] Gayheart JW, Moorman SA, Parsons TR, Poling CW. Babcock \& Wilcox Power Generation Group, Inc. RSATTM Process and Field Demonstration of the OptiCap ${ }^{\mathrm{TM}}$ Advanced Solvent at the US National Carbon Capture Center. Energy Procedia. 2013; 37: 1951-1967.

[54] Sharifzadeh M, Shah, N,. Carbon capture from natural gas combined cycle (NGCC) power plants: solvent performance comparison at industrial scale. AIChE Journal, 2015; in press, DOI: 10.1002/aic.15072. 
[55] Couper JR, Penney WR, Fair JR. Chemical Process Equipment Selection and Design (3rd edition). Burlington: Elsevier Science, 2012.

[56] Stone PM, Timmerhaus KD, West RE. Plant Design and Economics for Chemical Engineers (5th edition), London: McGraw-Hill Chemical Engineering Series, 2004.

[57] Electricity Wholesale Market [Internet]. Washington: US Energy Information Administration; US Department of Energy c2001-15 [cited 2015 April 8]. Available from: http://www.eia.gov/electricity/wholesale/

[58] Ulrich GD, Vasudevan PT. How to estimate utility costs, Chemical Engineering. 2006; April: 66-69.

[59] Grossmann IE. Advances in mathematical programming models for enterprise-wide optimization, Computers and Chemical Engineering. 2012; 47: 2-18.

[60] Sharifzadeh M, Thornhill NF. Optimal selection of control structures using a steady-state inversely controlled process model. Computers \& Chemical Engineering. 2012; 38: 126-138.

[61] Sharifzadeh M, Implementation of a steady-state inversely controlled process model for integrated design and control of an ETBE reactive distillation. Chemical Engineering Science. 2013; 92 (5): 21-39.

[62] Sharifzadeh M, Thornhill NF. Integrated design and control using a dynamic inversely controlled process model. Computers \& Chemical Engineering, 2013; 48: 121-134.

[63] gCCS: Whole chain CCS systems modelling, Process Systems Enterprise [Internet] [cited 2015 April 8], Available from: http://www.psenterprise.com/power/ccs/gccs.html).

[64] AML:GLC, Advanced Model Library - Gas-Liquid Contactors. Process Systems Enterprise [Internet] [cited 2015 April 8], Available from: http://www.psenterprise.com/processbuilder/libraries/aml glc.html)

[65] gSAFT, Process Systems Enterprise [Internet] [cited 2015 April 8], Available from: http://www.psenterprise.com/gproms/options/physprops/saft/). 


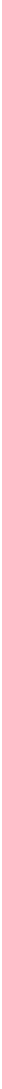

Graphical abstract: Multi-scale modelling of the capture process enables optimization at the plant-wide level 